\title{
Why demographic and modeling approaches should be adopted for estimating the effects of pesticides on biocontrol agents
}

\author{
John D. STARK ${ }^{1, *}$, Regina Lúcia SUGAYAMA ${ }^{2}$ and \\ Adalecio KOVALESKI ${ }^{3}$ \\ ${ }^{1}$ Puyallup Research and Extension Center, Washington State University, Puyallup, \\ WA, 98371, USA; ${ }^{2}$ AgroPEC - Pesquisa, Extensão e Consultoria Ltda, Caixa Postal \\ 177, CEP 95.200-000, Vacaria, RS, Brazil; ${ }^{3}$ Embrapa Uva e Vinho, Estacão \\ Experimental de Vacaria, Vacaria, RS, Brazil \\ *Author for correspondence: e-mail: starkj@wsu.edu
}

Received 14 April 2006; accepted in revised form 25 July 2006

\begin{abstract}
Recent studies have shown that simplistic measures of toxicity such as the $\mathrm{LC}_{50}$ do not provide enough information about the actual effects that may occur in pesticide-exposed populations over longer time periods than a few days. In this paper we discuss the use of demography and population modeling for estimation of pesticide effects on pest and beneficial species and argue that these new approaches are essential to further our understanding of the potential impacts that pesticides might have on both pest and beneficial species such as biological control agents.
\end{abstract}

Key words: life table response experiments, demography, models, toxicology, $\mathrm{LC}_{50}$, pesticides

\section{Introduction}

Traditionally, the effects of pesticides and other toxicants on organisms have been determined using simplistic measures of effect such as the $\mathrm{LD}_{50}$ or $\mathrm{LC}_{50}$ (lethal dose or concentration that kills $50 \%$ of a population). The scientific literature is full of such studies. Lethal concentration estimates are a straightforward approach that enables quick evaluation and comparison of several toxicants with regard to their effect on individuals of a particular species. It also brings the advantage of being relatively cheap to evaluate $\mathrm{LC}_{50}$ for several target and non-target species. The underlying assumption is that exposure of a given population to $\mathrm{LC}_{50}$ will reduce the number of individuals by 


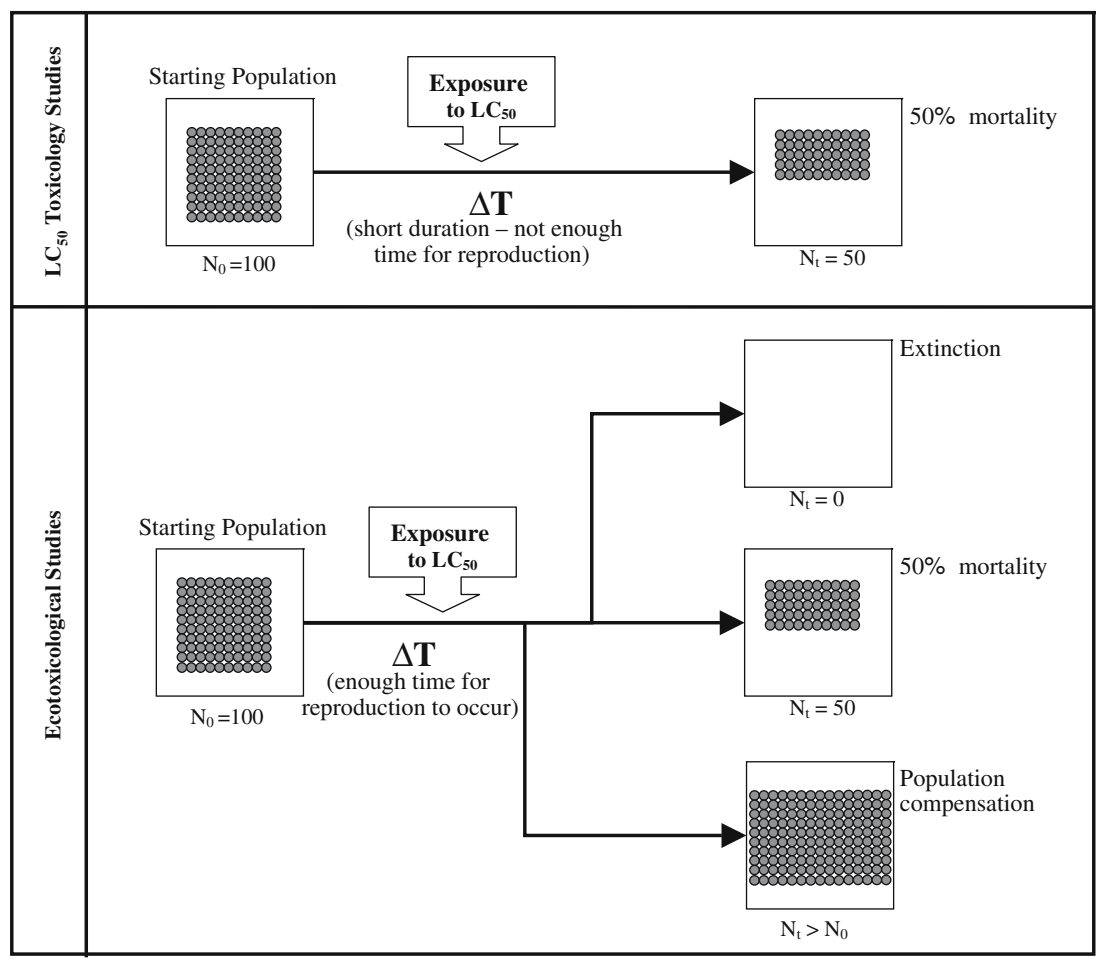

Figure 1. Possible population outcomes after exposure to a pesticide concentration equivalent to the $\mathrm{LC}_{50}$.

half (Figure 1) and there is no concern on the outcome of the $50 \%$ of individuals that survive exposure.

Results of several recent studies have indicated that new approaches for estimating the effects of pesticides and other toxicants on both pest and beneficial species are necessary to obtain a better understanding of the longer-term impacts that these products might have on ecosystems (Forbes and Calow, 1999; Stark and Banks, 2003; Stark, 2005).

The estimation of toxicant effects on populations is complicated by the fact that exposures can result in part of a population dying while surviving individuals may be impaired due to sublethal effects (Stark and Wennergren, 1995). Furthermore, some species can withstand high levels of mortality and recover quickly because they have high population growth rates, short generation times, early onset of reproductive activity or a combination of these attributes. Other species may become extinct after exposure to a toxicant at a concentration 
that does not kill all individuals because sublethal effects severely impact individuals.

Sublethal effects may impair individuals to such a degree that reproduction is not successful (Biddinger and Hull, 1999; Myers and Hull, 2003), lifespan is affected (Butter et al., 2003), male responsiveness to sexual pheromones is affected (Holscher and Barrett, 2003) and/or the ability to avoid predators is diminished due to morphological alterations (Butter et al., 2003, Josan and Singh, 2000). If, after exposure, some individuals survive, and these individuals reach reproductive age, various outcomes may occur. For example, multiple sublethal effects may occur resulting in eventual extinction (Figure 1). To further confound the issue, populations may compensate for losses of individuals. If, after exposure to a toxicant, sublethal effects do not occur but the population is reduced, surviving individuals may have more resources available and actually produce more offspring than control populations (Figure 1). This phenomenon is called population compensation.

Populations of different species do not react the same to equal levels of stress (Stark et al., 2004a) and thus the $\mathrm{LC}_{50}$ can not be used to compare effects of toxicants on populations over longer time intervals than a few days. Population effects will largely depend on life history traits.

It is difficult to measure both lethal and sublethal effects together in a meaningful way that scientists and IPM practitioners can understand. In many studies of toxicity, mortality and a measure of effect on reproduction are determined separately (Stark et al., 1990). The problem here is that it is difficult to ascribe an effect at the population-level using this approach.

Demography, or life tables, have been used in a small number of entomological studies to evaluate the total effects (lethal and sublethal) of toxicants on populations (see Stark and Banks, 2003 for a review of this subject). These types of studies are often called Life Table Response Experiments (LTREs). Carey (1993) has developed an excellent book on how to develop and use life tables with particular reference to arthropods.

When exposure to a toxicant kills all individuals, it is obviously unnecessary to use a life table approach. Additionally, when pesticide exposure does not cause sublethal effects, life tables are probably not very beneficial. To develop a life table, only two types of data are necessary; female survival and the number of female offspring produced by surviving females. Unlike the $\mathrm{LC}_{50}$ or other single measures of effect on individuals such as the NOEC for reproduction, several 
important population-level measures of pesticide effect can be developed from LTRE. Measurements developed in LTRE include the net reproductive rate $\left(R_{0}\right)$ (the per generation contribution of newborn females to the next generation), intrinsic birth rate (b) (the per capita instantaneous rate of birth in the stable population), intrinsic rate of increase $\left(r_{\mathrm{m}}\right)$ (the rate of natural increase in a closed population), lambda $(\lambda)$ (the population multiplication rate), and the stable age/ stage distribution (the proportion of each age class or stage in a stable population).

The most widely used measures of effect in LTRE are the intrinsic rate of increase or the population multiplication rate, because a total measure of population-level effect can be determined with one number. When $r_{\mathrm{m}}$ is zero, the population is stable (unchanging), when $r_{\mathrm{m}}$ is a positive number, the population is increasing exponentially, and when $r_{\mathrm{m}}$ is negative, the population is declining exponentially towards extinction. For $\lambda$, a value of 1 indicates a stable population, numbers greater than 1 indicate a growing population and numbers lower than 1 indicate a population in decline.

An example of the type of results that can be obtained with a life table toxicology study are presented in Table 1. In this example, the pea aphid, Acyrthosiphon pisum was exposed to the neem insecticide, Margosan-O (Stark and Wennergren, 1995). The acute LC $_{50}$ was estimated to be $27 \mathrm{mg} / 1(23-3395 \% \mathrm{CL})$. We see that as pesticide concentration increases, the net reproductive rate $\left(R_{0}\right)$, birth rate (b), generation time, intrinsic rate of increase and $\lambda$ all decline while death rate increases. Exposure to a concentration of $20 \mathrm{mg} / 1$, slightly lower than the $\mathrm{LC}_{50}$, results in a 5 -fold decrease in the net reproductive rate. This reproductive effect cannot be determined with acute mortality studies. After exposure to $60 \mathrm{mg} / 1$ the population growth rate becomes negative indicating that the population is headed towards

Table 1. Life table parameters of an unexposed population of the pea aphid, Acyrthosiphon pisum, and populations exposed to increasing concentrations of the neem insecticide, Margosan- $\mathrm{O}^{1}$

\begin{tabular}{lllllll}
\hline Concentration $(\mathrm{mg} / \mathrm{l})$ & $R_{0}$ & Birth rate & Death rate & Generation time & $r_{m}$ & \multicolumn{2}{c}{$\lambda$} \\
\hline Control & 80 & 0.35 & 0.07 & 13 & 0.27 & 1.31 \\
20 & 15 & 0.25 & 0.06 & 11 & 0.23 & 1.26 \\
40 & 3 & 0.17 & 0.13 & 9 & 0.15 & 1.16 \\
60 & 1 & 0.15 & 0.22 & 8 & -0.08 & 0.92 \\
\hline
\end{tabular}

${ }^{1}$ modified from Stark and Wennergren (1995). 
extinction. If this was an example of a beneficial organism that one intended to protect, then exposures should be lower than $40 \mathrm{mg} / 1$.

Clearly, there are great advantages to using demography for estimating the impacts of pesticides and other toxicants on biological control agents and other nontarget organisms.

Because $r_{\mathrm{m}}$ or $\lambda$ incorporates both lethal and sublethal effects into a single dimensionless number, these values are easy to understand and to compare. However, lethal concentration estimates have been shown to be much more limited and to have little predictive value at the population level (Stark, 2005).

There are also several disadvantages associated with the development of life tables for estimation of the effects of pesticides on populations. The primary disadvantage is that development of life tables is time consuming and expensive. Furthermore, there can be a lack of realism in LTRE depending upon how the studies are conducted. LTRE conducted in the field will provide more accurate data than laboratory studies. However, these factors are not considered in the traditional toxicological approach either.

Overmeer and Van Zon (1982) proposed a method that incorporates mortality and effects on fecundity into a measure called the "Total Effect Index" or "E". This approach has been used by some researchers (Blumel and Gross, 2001; Castagnoli et al., 2002; Kavousi, and Talebi 2003). However, in a recent paper, the Total Effect Index was compared to LTREs (Rezaei et al. in press). Rezaei et al. (in press) found LTREs to be more sensitive for the assessment of pesticide effects on nontarget organisms than the Total Effect Index.

\section{Matrix models}

Life table data developed in demographic studies can be used in models to predict (ordinary or partial differential equation models) (Banks et al. in press) or project (matrix models) populations (Wennergren and Stark, 2000). Several excellent texts on the use of matrices in biology are available (Carey, 1993; Caswell, 2000).

Matrix models are used to project population growth into the future based on present day conditions. For example, based on the population size, birth rate, death rate, immigration and emigration of the European Union today, demographers can project what would occur 50 years from now assuming no major changes in the above mentioned parameters occur over the next 50 years. The same principles can be applied to pest or beneficial populations that have been 
exposed to pesticides. The data used in matrix models are female survival and number of female offspring (eq.1). In equation $1, P$ values (survivorship) are placed on the subdiagonal while $F$ values (Fecundity) run along the top of the matrix. The vector, $\left.\mathrm{n}_{(\mathrm{t}}\right)$, represents the condition of the starting population and consists of numbers of individuals in each stage or age category $\left(\mathrm{n}_{1}, \mathrm{n}_{2}, \mathrm{n}_{3}\right.$ etc.). In its simplest form, 10 individuals would be placed in the $n_{1}$ section of the vector and zeros in the other $\mathrm{n}$ values. This would represent a population starting as all eggs or neonates depending upon the life history of the species. The vector is then multiplied by the matrix to get the next vector, $\left.\mathrm{n}_{(\mathrm{t}}+1\right)$. The new vector, $\left.\mathrm{n}_{(\mathrm{t}}+1\right)$ is then multiplied by the matrix to get the next vector, $\left.\mathrm{n}_{(\mathrm{t}}+2\right)$ and so on, thus projecting the population forward in time. The time interval for each matrix multiplication must be established, and is usually based on the time interval used to construct the life table. For insects, survival and fecundity can be measured daily and thus the time step in the matrix projection model might be one day.

Additionally, changes that occur to specific life history traits (reductions in fecundity or survival for example) can be evaluated with sensitivity and elasticity analysis (Caswell, 2000). Recently, these techniques have been used by entomologists (Kim et al., 2004).

$$
\left(\begin{array}{c}
n_{1} \\
n_{2} \\
n_{3} \\
\vdots \\
n_{z}
\end{array}\right)(t+1)=\left(\begin{array}{ccccc}
F_{1} & F_{2} & F_{3} & \cdots & F_{z} \\
p_{1} & 0 & 0 & \cdots & 0 \\
0 & P_{2} & 0 & \cdots & 0 \\
\vdots & \cdots & \cdots & \cdots & \vdots \\
0 & 0 & \cdots & P_{z-1} & 0
\end{array}\right)\left(\begin{array}{c}
n_{1} \\
n_{2} \\
n_{3} \\
\vdots \\
n_{z}
\end{array}\right)(t)
$$

An example of a matrix projection model is presented in Figure 2. Here a hypothetical population of the seven spot ladybeetle, Coccinella septempunctata (C-7) is unexposed (control), exposed to a pesticide that causes $50 \%$ mortality only, a $50 \%$ reduction in the number of offspring produced, or a combination of mortality and reduction in offspring (lethal and sublethal effects). We see that the 50\% reduction in offspring has the least effect on the population. Fifty percent mortality reduces the population more than a $50 \%$ reduction in offspring and the combination of both effects causes the greatest decline.

In another example of matrix projections, populations of the aphid parasitoid, Diaeretiella rapae and the C-7 lady beetle are compared (Figure 3). It is evident from this example that population growth rates of unexposed populations are quite different; the parasitoid population grows at a much faster rate than the predator. Exposure to a 


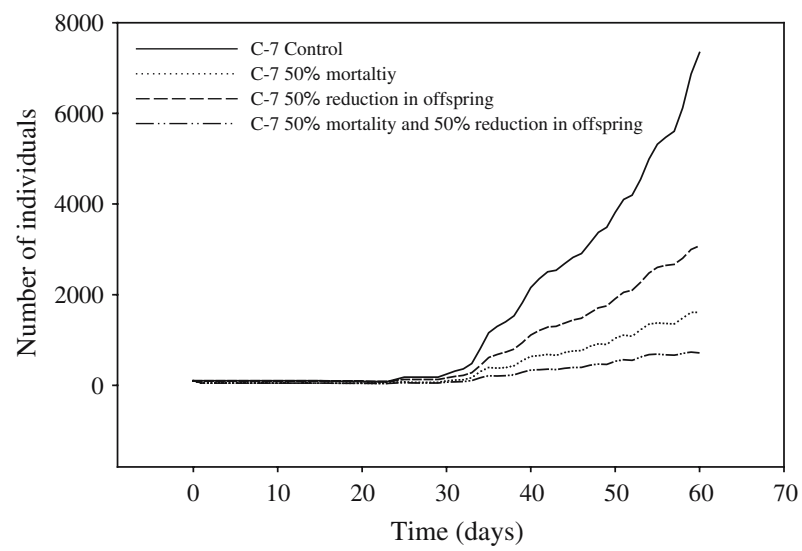

Figure 2. Example of matrix projection model based on life table parameters. This species, the seven spot lady beetle, Coccinella septempunctata L. (C-7) has been subjected to either $50 \%$ mortality, $50 \%$ reduction in offspring or a combination of both effects.

lethal and sublethal effect causes a severe reduction in growth of both populations.

A recent application of matrix models is to compare population delays caused by various stressors such as pesticides (Wennergren, and Stark 2000; Stark et al., 2004b). The Delay in Population Growth Index (Wennergren and Stark, 2000, Stark et al., 2004b) is a measure of population recovery that compares control populations to those exposed to specified levels of mortality and/or reductions in offspring.

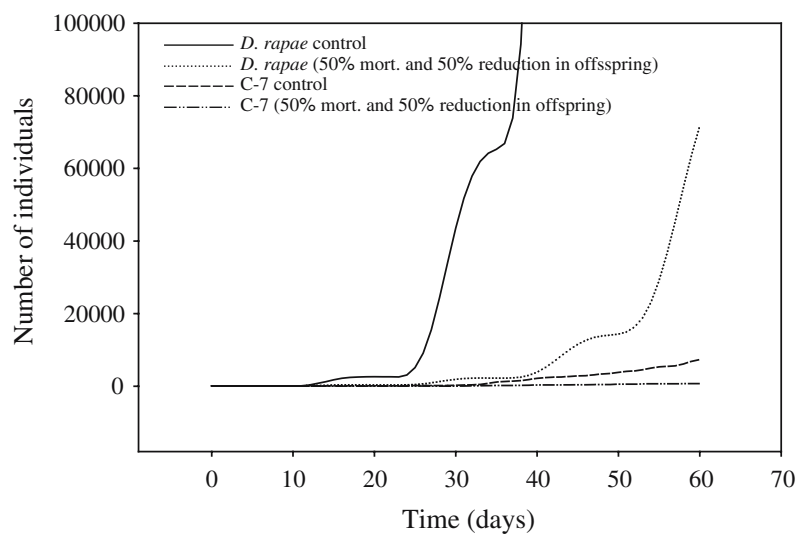

Figure 3. Comparison of matrix model projections of the aphid parasitoid, Diaeretiella rapae and the $\mathrm{C}-7$ lady beetle, Coccinella septempunctata unexposed and exposed to a hypothetical pesticide that causes $50 \%$ mortality and a $50 \%$ reduction in offspring. 
Population delays are determined by choosing a population size (number of individuals) and comparing the time it takes for a control population and a stressed population to reach the predetermined number of individuals.

Matrix models are also useful for making comparisons among different toxicants. In a recent study, lethal and sublethal effects of eight insect growth regulators on the tortricid Bonagota cranaodes (Meyrick) were evaluated (Sugayama et al. in press). Even those pesticides that did not cause immediate extinction due to strong ovicidal and/or larvicidal effects led to population extinction due to combined lethal and sublethal effects.

\section{Conclusions}

Although the demographic approach has not been widely adopted to date, this method obviously provides more information about pesticide effects on populations than acute $\mathrm{LC}_{50}$ studies. In addition, matrix models are particularly valuable for comparisons of populations exposed to various concentrations of pesticides (Stark et al., 2004b) or different pesticides (Sugayama et al. in press).

It might be argued that this approach is not realistic and that results of matrix model simulations cannot be used to predict what is going to happen under natural conditions with a high degree of confidence. However, this is not the aim of these types of studies. The advantage of adopting matrix modeling is that it enables an estimate of the least damaging concentration when one wishes to protect a particular species. Also, it may indicate what toxicants are or are not expected to lead to effective pest control.

To make progress in integrated pest management and the protection of nontarget, threatened and endangered species, demography and modeling should be adopted to better estimate the potential impacts on biological control agents and other beneficial species.

\section{References}

Banks, H.T., J.E. Banks, L.K. Dick and J.D. Stark Estimation of dynamic rate parameters in insect populations undergoing sublethal exposure to pesticides. Bull. Math. Bio. (in press).

Biddinger, D.J. and L.A. Hull, 1999. Sublethal effects of selected insecticides on growth and reproduction of a laboratory susceptible strain of tufted apple bud moth (Lepidoptera: Tortricidae). J. Econ. Entomol. 92: 314-324. 
Blumel, S. and M. Gross, 2001. Effect of pesticide mixtures on the predatory mite Phytoseiulus persimilis AH (Acarina, Phytoseiidae) in the laboratory. J. Appl. Entomol. 125: 201-205.

Butter, N.S., G. Singh and A.K. Dhawan, 2003. Laboratory evaluation of the insect growth regulator lufenuron against Helicoverpa armigera in cotton. Phytoparasitica 31: 200-203.

Carey, J.R., 1993. Applied demography for biologists with special emphasis on insects. Oxford University Press, New York.

Castagnoli, M., G. Angeli, M. Liguori, D. Forti and S. Simoni, 2002. Side effects of botanical insecticides on predatory mite Amblyseius andersoni (Chant). Anzeiger fur Schadlingskunde 75: 122-127.

Caswell, H., 2000. Matrix population Models: Construction, Analysis and Interpretation. 2nd edSinauer Associates Inc., Sunderland, Massachusetts.

Forbes, V.E. and P. Calow, 1999. Is the per capita rate of increase a good measure of population-level effects in ecotoxicology? Environ. Toxicol. Chem. 18: 1544-1556.

Holscher, J.A. and B.A. Barrett, 2003. Effects of methoxyfenozide-treated surfaces on the attractiveness and responsiveness of adult codling moth (Lepidoptera: Tortricidae). J. Econ. Entomol. 96: 623-628.

Josan, A. and G. Singh, 2000. Sublethal effects of lufenuron on the diamondback moth, Plutella xylostella (Linnaeus). Ins. Sci. Applic. 20: 303-308.

Kavousi, A. and K. Talebi, 2003. Side-effects of three pesticides on the predatory mite, Phytoseiulus persimilis (Acari : Phytoseiidae). Exp. App. Acarol. 31: 51-58.

Kim, M., D. Shin, E. Suh and K. Cho, 2004. An assessment of the chronic toxicity of fenpyroximate and pyridaben to Tetranychus urticae using a demographic bioassay. Appl. Entomol. Zool. 39: 401-409.

Myers, G.A. and L.A. Hull, 2003. Insect growth regulator impact on fecundity and fertility of adult tufted apple bud moth, Platynota idaeusalis Walker. J. Entomol. Sci. 38: $420-430$.

Overmeer, W.P.J. and A.Q. van Zon, 1982. A standardized method for testing the sideeffects of pesticides on the predacious mite Amblyseius andersoni (Acarina: Phytoseiidae). Entomophaga 27: 357-364.

Rezaei M., K. Talebi, N. Hosseini and A. Kavousi. Impacts of the pesticides imidacloprid, propargite and pymetrozine on Chrysoperla carnea (Stephans) (Neuroptera: Chrysopida): using IOBC and lifae table assays. BioControl. (in press).

Stark, J.D., R.I. Vargas and R.K. Thalman, 1990. Azadirachtin: Effects on metamorphosis, longevity, and production of three Tephritid fruit fly species (Diptera: Tephritidae). J. Econ. Entomol. 83: 2168-2174.

Stark, J.D. and U. Wennergren, 1995. Can population effects of pesticides be predicted from demographic toxicological studies? J. Econ. Entomol. 88: 1089-1096.

Stark, J.D. and J.E. Banks, 2003. Population-level effects of pesticides and other toxicants on arthropods. Annu. Rev. Entomol. 48: 505-519.

Stark, J.D., J.E. Banks and S. Acheampong, 2004a. Estimating susceptibility of biological control agents to pesticides: influence of life history strategies and population structure. Biol. Control 29: 392-398.

Stark, J.D., J.E. Banks and R.I. Vargas, 2004b. How risky is risk assessment? The Role that Life History Strategies Play in Susceptibility of Species to Stress 2004. Proc. Nat. Acad. Sci. 101: 732-736.

Stark, J.D., 2005. How closely do acute lethal concentration estimates predict effects of toxicants on populations?. Integrated Environ. Assess. Manage. 1: 109-113. 
Sugayama, R., A. Kovaleski and J.D. Stark. A demographic modeling approach for the evaluation of the effects of eight insect growth regulators on Bonagota cranaodes (Meyrick) (Lepidoptera: Tortricidae), a key pest of apples in Brazil. Neotropical Entomol. (in press).

Wennergren, U. and J.D. Stark, 2000. Modeling long-term effects of pesticides on populations: beyond just counting dead animals. Ecol. Appl. 10: 295-302. 